Research Article

\title{
Research on Calculation Method for Maximum Mean Acceleration in Longitudinal Train Collision
}

\author{
Jingke Zhang $\mathbb{D}^{1},{ }^{1}$ Xiaorui Wang $\mathbb{D}^{1},{ }^{1}$ Tao Zhu $\mathbb{D},{ }^{1}$ Bing Yang, ${ }^{1}$ Shoune Xiao, ${ }^{1}$ \\ Guangwu Yang, ${ }^{1}$ Yanwen Liu, ${ }^{2}$ and Benhuai $\mathrm{Li}^{2}$ \\ ${ }^{1}$ State Key Laboratory of Traction Power, Southwest Jiaotong University, Chengdu 610031, China \\ ${ }^{2}$ Basic R\&D Department, National Railway Passenger Car Engineering Research Center, Changchun Railway Vehicles Co., Ltd, \\ Changchun 130062, China
}

Correspondence should be addressed to Tao Zhu; zhutao034@swjtu.cn

Received 9 July 2021; Accepted 4 September 2021; Published 20 September 2021

Academic Editor: Cristina Castejón

Copyright (C) 2021 Jingke Zhang et al. This is an open access article distributed under the Creative Commons Attribution License, which permits unrestricted use, distribution, and reproduction in any medium, provided the original work is properly cited.

\begin{abstract}
A large number of numerical simulations are required to design an energy absorption scheme for train crashworthiness, leading to low design efficiency in the early stage. Based on train collision dynamics theory and the finite element method, a dynamic finite element model of longitudinal train collision is established. According to the model, we studied the acceleration time-history characteristics during the train collision process, obtained the mean-peak ratio coefficient, and determined the calculation formula for the maximum mean acceleration of a longitudinal train collision. Through characteristic analysis of the vehicle acceleration, interface force, and other parameters during a longitudinal train collision, the calculation method of the mean acceleration was improved. The analysis shows that the maximum mean acceleration depends on two stages in the collision process: (1) the coupler action of the head vehicle: the mean-peak ratio coefficient of the head vehicle is 0.7 in this stage, and the mean-peak ratio coefficient of other vehicles is 0.43 ; (2) the coupler of the collision interface is cut off, and the energy absorption devices of the head vehicle or intermediate vehicle absorb energy; the mean-peak ratio coefficient of the vehicle is 0.93 in this stage. On this basis, a mathematical function is established describing the mean acceleration of the vehicle and the average crushing force of the coupler collapse tube and the energy-absorbing device. The calculation formula is obtained for the maximum mean acceleration of the longitudinal train collision, and the results are compared with the mean acceleration obtained by numerical simulation. The Kruskal-Wallis ANOVA multisample independent nonparametric test was conducted to verify the reliability of the calculation results in the $95 \%$ confidence interval. The calculation formula can be used to calculate the maximum mean acceleration in the energy allocation stage of train crashworthiness design to effectively improve the efficiency of train collision energy allocation.
\end{abstract}

\section{Introduction}

In the past few decades, a large number of train collision safety research projects have been carried out in continental Europe, the United Kingdom, the United States, and China, and the passive safety research of trains in crash energy management, structural crashworthiness design, crash instability behavior, collision simulation modeling technology, crash test technology, and test bench construction has made great progress. Based on the Mark I $\sim$ Mark III vehicles, the UK has formed a complete train crashworthiness theory through in-depth research on its crashworthiness and formulated the Railway Group Standard GM/RT2100 standard to guide the crashworthiness design of vehicles [1-3]. With the development of high-speed railways, Continental Europe has carried out a series of train crashworthiness research projects represented by TRAINCOL, SAFETRAIN, SAFETRAM, and SAFE INTERIORS [4-7], which led to the formation of the EN 15227 standard. The United States conducted six vehicle crash tests between 1999 and 2005, systematically summarized the crashworthiness design methods of rail vehicles, proposed the concept of train crash energy management, and formed the 49CFR229 railroad locomotive safety standards and 49CFR238 
passenger equipment safety standards [8-11]. Based on the above experimental research, the researchers verified the feasibility and accuracy of the longitudinal train collision dynamic model to simulate the acceleration change during the train collision process and configure the train energy absorption scheme [12] and proposed the traditional calculation method of the maximum mean acceleration of train collision and the acceleration index that needs to be met.

Based on the above research results, at present, researchers have formed a train crashworthiness design method, which mainly takes collision energy management as the guiding ideology and sets a multilevel energy absorption system [13] including coupler buffer device, energy absorption device, and energy absorption area at the end of the car body. The energy absorption structure can be plastically deformed in a controllable manner to absorb the collision kinetic energy and reduce injury to the occupants. When designing the crashworthiness of a train, the reference standard for the crashworthiness design of the vehicle structure must be first determined. With the requirements of the standard framework, the energy of each part of a marshaling train is allocated based on the crash energy management principle [14]; the first step in train crashworthiness design is crash energy management. Based on the theory of train collision dynamics, the known vehicle weights, marshaling, and other basic information, a longitudinal train collision dynamics program is developed, a series of numerical simulation calculations are conducted for collision energy allocation schemes, and the maximum mean acceleration of each vehicle and its energy absorption rate during the collision are obtained. The optimal energy allocation plan is determined based on the calculation results [15-17]. This process requires many numerical simulation calculations and consumes considerable computational time, resulting in low predesign efficiency. The main causes of occupant casualties in train collision accidents are the secondary collision between the occupant and the train, the loss of occupant space, and high deceleration [18]. For occupant protection, train crashworthiness design allows the car body to withstand orderly and controllable forces. To ensure occupant space, the car body structure must remain within an acceleration range that occupants can withstand, without excessive deceleration.

Based on the finite element model of the longitudinal train crash dynamics, the relationship between the mean acceleration of each car and the energy allocation scheme parameters is determined. In the collision energy allocation stage, the maximum mean acceleration of each vehicle is estimated for the energy allocation scheme without numerical calculation, which is of great significance for improving the crash resistance design efficiency of trains.

As an effective means of studying longitudinal train collision behavior, the longitudinal collision dynamics model can better reflect the energy change of each interface and the change in vehicle acceleration during a train collision. To accurately simulate the mechanical performance of the coupler draft gear during a train collision, Xiao et al. proposed a modeling method for the coupler draft gear based on the discrete beam unit in LS-DYNA that simulated the mechanical characteristics and energy absorption of the train coupler draft gear and the failure or fall-off of the coupler device under the limit load $[19,20]$. Based on the traditional spring mass model, Qin et al. proposed a simplified modeling method for the vehicle body during a train collision based on nonlinear rod elements and provided a parameter correction method for the simplified car body unit. The calculation results were in good agreement with the calculation results of the three-dimensional collision dynamics model of the train [21]. Xu and Xie et al. conducted equivalent scale one-dimensional and three-dimensional collision tests of train and energy-absorbing structure [22-27], which verified the accuracy of one-dimensional and three-dimensional train collision dynamics models and the effectiveness of the numerical simulation of the energyabsorbing structure in terms of speed, acceleration, and interface force.

A longitudinal collision dynamics model can be used for train crash energy management and longitudinal train collision (or impact) behavior analysis. For crash energy management, a one-dimensional longitudinal collision dynamics model of the train is established in the early stage of crashworthiness design. The relationships between the energy absorption of each interface and the initial collision kinetic energy of the train, the number of train formations, and the crushing platform force of the energy-absorbing structure are studied. The relationship between the energy absorption capacity of the collision interface and each parameter is determined to provide the initial value of the energy allocation scheme [15, 28-32].

A comprehensive evaluation method was introduced in the design process of the train collision energy configuration scheme. Using the maximum mean acceleration, energy utilization rate, and maximum instantaneous acceleration as evaluation indexes, a comprehensive evaluation model of the one-dimensional collision energy configuration scheme is constructed to scientifically and objectively evaluate different energy configuration schemes [33]. Based on the established longitudinal dynamic model of the train, the influences of different train parameters and energy configuration parameters on the longitudinal collision behavior of the train $[16,34-36]$, the longitudinal impact during startup, stop, and operation of the train [37], the influence of the triggering mechanism of the coupler shear device on the structural damage of the car body [38], and the transmission of stress waves during train collisions [39] are studied.

There are two significant threats to occupants during a train collision. One is the loss of the occupant space, causing direct injury; the other is excessive deceleration, causing a secondary collision between the occupant and the vehicle, indirectly causing injury. Excessive deceleration is mostly due to unreasonable energy allocation, leading to drastic changes in vehicle speed during a collision. Studying the acceleration time-history characteristics in the train collision process and establishing the relationship between acceleration and energy configuration parameters are significant in the design of train collision resistance. Using existing modeling methods for energy-absorbing structures such as a coupler draft gear and energy-absorbing devices $[19,20]$, a 
dynamic model of longitudinal train collision based on the finite element analysis method is established for in-depth study of the relationship between the mean acceleration of each vehicle in different energy allocation schemes and the parameters of the energy allocation scheme, the introduction of the steady-state force mean acceleration and the meanpeak ratio parameters, and establishment of a calculation method for the maximum mean acceleration of a train in a longitudinal collision.

\section{Dynamic Finite Element Model of Longitudinal Train Collision}

2.1. Multistage Energy Absorption System for Trains. A typical multistage energy absorption system at the end of a train is shown in Figure 1. A crash zone contains several structural elements with a predictable and controllable response to meet the requirements of energy absorption to prevent passenger injury. The energy absorption structure at the end of the head vehicle includes four parts: (I) a draft gear; (II) a couple collapse tube; (III) an anticlimbing device and an energy-absorbing device; (IV) a nondeformable space. The energy absorption structure at the end of the intermediate vehicle consists of four parts: (I) a draft gear; (II) a couple collapse tube; (III) a couple collapse tube and an anticlimbing device; (IV) a nondeformable space.

2.2. Longitudinal Collision Dynamics Model of Train. By considering the end structure as a nonlinear spring and replacing the central passenger area with mass points, a onedimensional or three-dimensional collision dynamics model of the train can be established. The model can be used to study the collision safety of passengers and crash energy management $[12,40,41]$.

2.2.1. Model Assumptions. The longitudinal rigidity of the car body is much greater than that of the draft gear, energyabsorbing device, and anticlimbing device. Thus, when studying the longitudinal collision dynamics of a train, the car body structure is generally simplified as a rigid body of a concentrated mass model. The masses of the draft gear, energy-absorbing device, and anticlimbing device are much smaller than those of the car body and are ignored in modeling. The draft gear has only the functions of connecting and energy absorption. Based on previous research results, simplified longitudinal collision dynamics model, the following assumptions were made [12, 42]:

(1) The vehicle is equivalent to a homogeneous rigid body; the mass is shown in Table 1

(2) Two identical trains collide head-on on a straight track, ignoring the influence of track irregularities

(3) The longitudinal impact force of the train is far greater than the external resistance, ignoring the aerodynamic resistance and wheel-rail friction of the train
(4) Only the longitudinal tension and compression energy absorption characteristics of the energy-absorbing structure are considered, ignoring the influence of lateral and vertical movement, and the fluctuation of the force value in the collapse stage

2.2.2. Model Building. Using the discrete beam element modeling method and MAT119 material $[19,20]$, a mechanical model is established that can represent the coupler draft gear, energy-absorbing device, and nondeformation zone in the collision process. The mechanical characteristic input curves of the coupler buffer device and the energyabsorbing device use data from the literature [43], as shown in Figure 2. The force-time curve during the impact process is obtained from the car body structure impacting the rigid wall, and the average value is obtained through force equivalence [44] as the mechanical characteristic input curve of the nondeformation zone, as shown in Figure 3. The crushing force of the nondeformed area of the head vehicle was $6000 \mathrm{kN}$; the crushing force of the nondeformed area at the end of the intermediate vehicle was $9000 \mathrm{kN}$.

Based on the assumptions and the simplified impact mechanical properties of the end and middle interface of the train, a longitudinal collision dynamics model reflecting the energy absorption characteristics of the energy absorption structure between the trains is established in LS-DYNA collision dynamics software. The train marshaling is shown in Figure 4, and the marshaling mass is presented in Table 1.

In Figure 4, 1M-2M-15M-16M represents the connection interface between the moving vehicles; 1S-2S-15S-16S represents the connection interface between the stationary vehicles; $M$ represents the moving train, and $S$ represents the stationary train; $16 \mathrm{M}-16 \mathrm{~S}$ represents the collision interface of two trains; only some of the interface numbers are shown in the figure.

Based on the established longitudinal train collision finite element model, an in-depth study of the acceleration time-history characteristics of the car body structure (also known as the passenger zone) during the train collision process improves the mean acceleration calculation method; the ratio of the mean acceleration to the peak acceleration or steady-state force acceleration is calculated (mean-peak ratio), and the calculation formula for the maximum mean acceleration of the train collision is established.

\section{Calculation Method for Mean Acceleration of Longitudinal Train Collision}

3.1. Traditional Mean Acceleration Calculation Method. The maximum mean acceleration, as an important evaluation index for occupant safety in train collisions, has always been a research focus. The train crashworthiness assessment standard EN 15227:2020 requires that the mean acceleration of the car body structure does not exceed $5 \mathrm{G}$ within $120 \mathrm{~ms}$ or $10 \mathrm{G}$ within $30 \mathrm{~ms}$. The calculation method is described as follows: the mean acceleration (MA) in survival spaces should be limited as far as it is practicable to $5 \mathrm{G}$ (as required by EN 15227). 


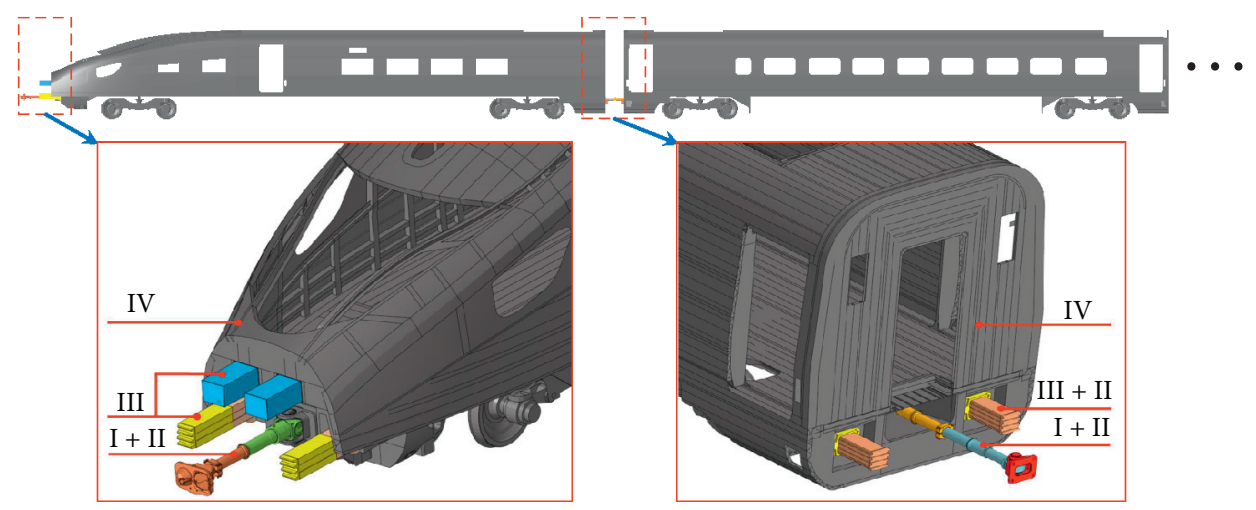

(a)

(b)

Figure 1: Multistage energy absorption system at end of car body.

TABLE 1: Train marshaling mass.

\begin{tabular}{lc}
\hline Vehicle number & Collision mass $(\mathrm{t})$ \\
\hline $1 \mathrm{M}$ & 55.722 \\
$2 \mathrm{M}$ & 57.949 \\
$3 \mathrm{M}$ & 59.964 \\
$4 \mathrm{M}$ & 58.608 \\
$5 \mathrm{M}$ & 58.608 \\
$6 \mathrm{M}$ & 59.964 \\
$7 \mathrm{M}$ & 58.608 \\
$8 \mathrm{M}$ & 50.677 \\
$9 \mathrm{M}$ & 54.284 \\
$10 \mathrm{M}$ & 58.608 \\
$11 \mathrm{M}$ & 59.964 \\
$12 \mathrm{M}$ & 58.608 \\
$13 \mathrm{M}$ & 58.608 \\
$14 \mathrm{M}$ & 59.964 \\
$15 \mathrm{M}$ & 57.949 \\
$16 \mathrm{M}$ & 55.722 \\
\hline
\end{tabular}

$$
\mathrm{MA}_{i}=\frac{\sum_{t_{s}}^{t_{e}} \operatorname{Acc}(t)}{t_{e}-t_{s}}
$$

where $\operatorname{Acc}_{i}(t)$ is the instantaneous longitudinal acceleration in the $i^{\text {th }}$ car body mass center of a train and $t_{s}$ and $t_{e}$ are the times when the net contact force on the vehicle exceeds zero and when it next returns to zero, respectively.

For the two energy configuration schemes in Table 2, compared with the initial scheme in literature [43], the difference between Scheme 1 and Scheme 2 is that the average crushing force of the collapse tube and energy-absorbing device of the head vehicle are changed; the other parameters remain unchanged.

In a train collision, the energy absorption, interface force, speed, and acceleration of the car body structure exhibit a certain symmetry. This study uses a moving train as an example for analysis.

Figure 5 shows the acceleration curve of the car body structure during a train collision. Because the acceleration oscillation is caused mainly by the loading and unloading of the interface force in the late stage of the collision, the figure only shows the acceleration curve of the head car body of the moving train at the collision interface from 0 to $1.06 \mathrm{~s}$.
The mean acceleration calculated according to (1) is shown in Table 3, collectively referred to as acceleration, where a negative value indicates deceleration, and a positive value indicates acceleration.

For scheme 2, the car body has a small acceleration from 0.08 to $0.21 \mathrm{~s}$; the mean acceleration from 0 to $0.08 \mathrm{~s}$ is approximately twice that from 0 to $0.22 \mathrm{~s}$. Thus, if (1) is indiscriminately used to calculate the mean acceleration, the acceleration of the passengers from 0 to $0.08 \mathrm{~s}$ in scheme 2 is greater than the calculated value, compromising the crashworthiness design of the car body structure.

3.2. Improved Mean Acceleration. Combining the crushing force of the couple collapse tube in Table 2 and the analysis in Figure 6, it can be found that the reason for the acceleration at this stage is due to the different crushing force of the couple collapse tube of head vehicle and middle vehicle. At present, the crushing force of the couple collapse tube of the head vehicle and middle vehicle is generally not significantly different, and the acceleration acting on the body structure during the crushing process is generally a few tenths of $g$, which is far less than the requirements of the assessment index. Therefore, the smaller acceleration value at this stage can be ignored in the calculation process.

From the perspective of occupant safety, when using (1) to calculate the mean acceleration of the car body, if the acceleration period is long, removing the period with smaller acceleration, such as the acceleration from 0.08 to $0.21 \mathrm{~s}$ in scheme 2 (Figure 5), is recommended. This method is used to calculate the mean-peak ratio, known as the improved mean acceleration (IMA).

\section{Analysis of Train Collision Process}

According to the cutting time of the coupler of the head car and the energy absorption time of the energy-absorbing device of the intermediate car interface, the acceleration of the car body is divided into three stages: stage 1 is the action stage of the head car coupler; in stage 2, the coupler of the front end of the head vehicle is cut off (the end of the head vehicle close to the collision interface $16 \mathrm{M}-16 \mathrm{~S}$ is the front end; the other end is the rear end), and the energy-absorbing 


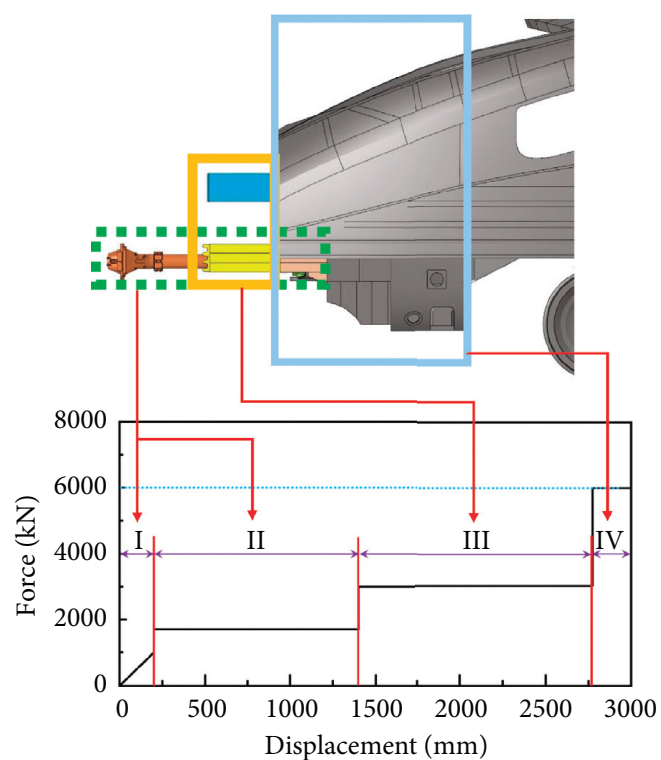

(a)

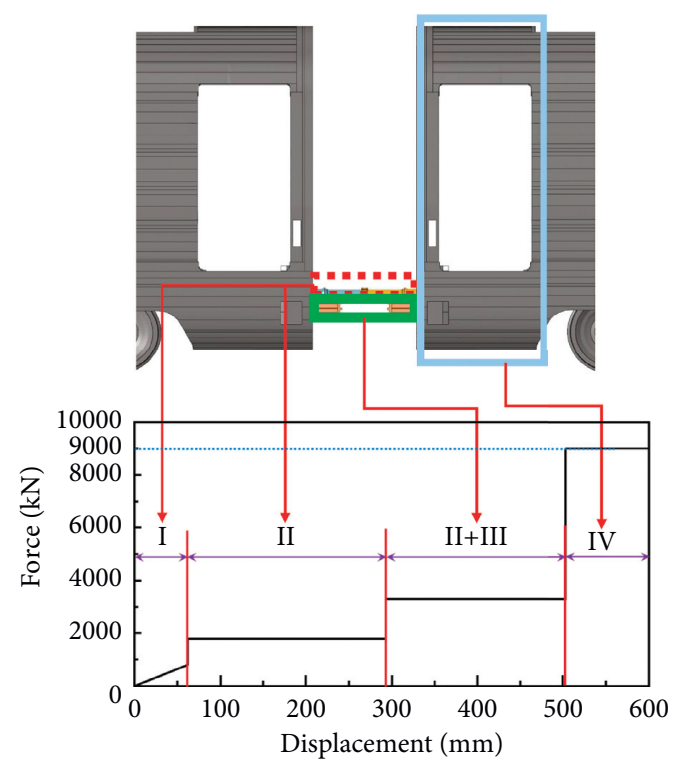

(b)

Figure 2: Design of crush zone structures and force-displacement characteristics. (a) HE zone. (b) LE zone.

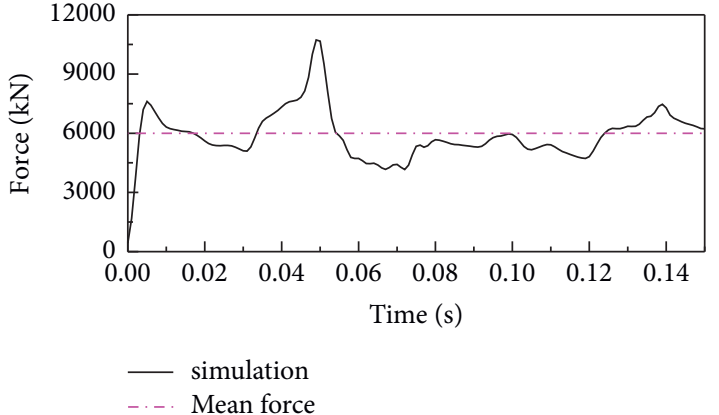

(a)

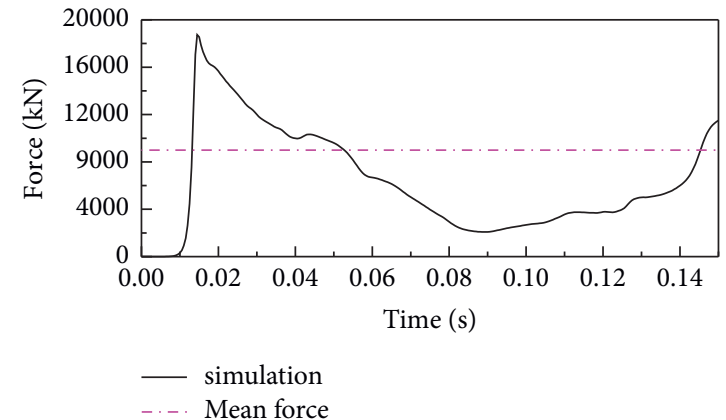

(b)

Figure 3: Collapse force-time curve of car body structure. (a) Head car. (b) Intermediate car.

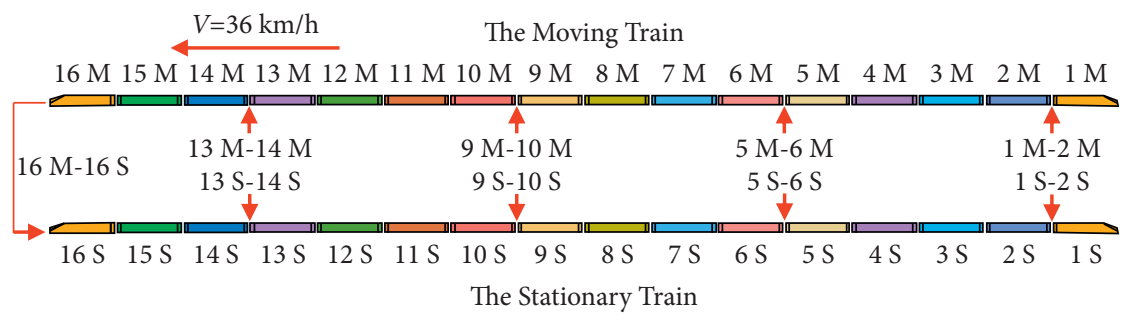

FiguRe 4: Diagram of train collision conditions.

device of the head car or the intermediate car participates in the energy absorption stage; stage 3 is the acceleration oscillation stage caused by interface force loading and unloading; the maximum mean acceleration is not generated in this stage, and it is not the focus of this research.

To facilitate derivation of the formula, the following parameters are defined: (1) peak acceleration: the maximum value of the acceleration in stage 1 is in Figure 7. At this time, the front end coupler collapse tube of the head vehicle participates in energy absorption, and the rear end coupler is in the draft gear compression stage; (2) steady-state force acceleration: the stable acceleration value in stage 2 is in Figure 7; (3) steady-state force: the force that produces steady-state acceleration is shown in Figure 7; the force of interface $9 \mathrm{M}-10 \mathrm{M}$ minus the force of interface $8 \mathrm{M}-9 \mathrm{M}$ in stage 2 is the resultant force at both ends of the vehicle. 
TABLE 2: Energy configuration scheme of energy-absorbing structure.

\begin{tabular}{|c|c|c|c|c|}
\hline \multicolumn{3}{|c|}{ Energy-absorbing structure type } & Scheme 1 & Scheme 2 \\
\hline \multirow{4}{*}{ Head car coupler } & \multirow{2}{*}{ Collapse tube } & Maximum crushing stroke $(\mathrm{mm})$ & 600 & 600 \\
\hline & & Average crushing force $(\mathrm{kN})$ & 1800 & 2000 \\
\hline & \multirow{2}{*}{ Draft gear } & Maximum load $(\mathrm{kN})$ & 1000 & 1000 \\
\hline & & Maximum stroke (mm) & 100 & 100 \\
\hline \multirow{2}{*}{\multicolumn{2}{|c|}{$\begin{array}{l}\text { Energy absorbing device at the collision } \\
\text { interface }\end{array}$}} & Maximum crushing stroke $(\mathrm{mm})$ & 900 & 900 \\
\hline & & Average crushing force $(\mathrm{kN})$ & 2800 & 3300 \\
\hline \multirow{4}{*}{ Middle car coupler } & \multirow{2}{*}{ Collapse tube } & Maximum crushing stroke $(\mathrm{mm})$ & 438 & 438 \\
\hline & & Average crushing force $(\mathrm{kN})$ & 1800 & 1800 \\
\hline & \multirow{2}{*}{ Draft gear } & Maximum load (kN) & 800 & 800 \\
\hline & & Maximum stroke (mm) & 62 & 62 \\
\hline \multirow{2}{*}{\multicolumn{2}{|c|}{$\begin{array}{l}\text { Energy absorbing device at the middle } \\
\text { interface }\end{array}$}} & Maximum crushing stroke (mm) & 210 & 210 \\
\hline & & Average crushing force $(\mathrm{kN})$ & 1500 & 1500 \\
\hline
\end{tabular}

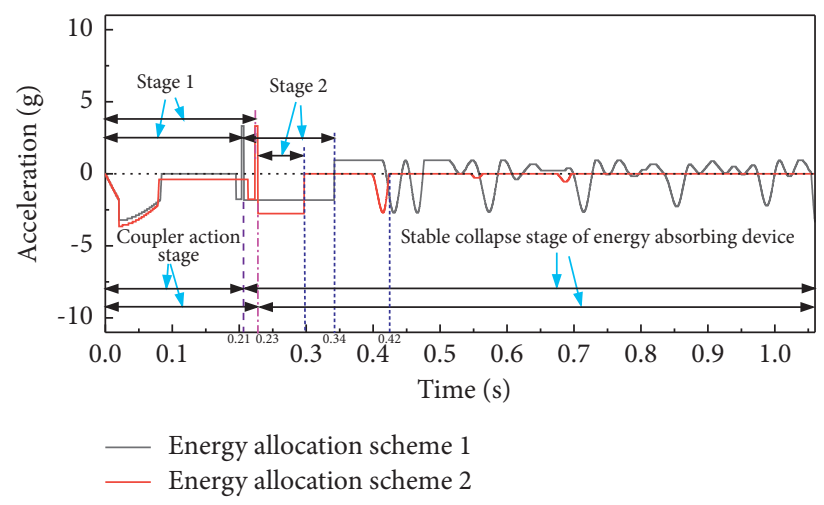

FIgURE 5: Lead car body acceleration-time curve from 0 to $1.06 \mathrm{~s}$.

TABle 3: Mean acceleration of car body structure.

\begin{tabular}{lccc}
\hline Scheme & Scheme 1 $(0 \sim 0.22 \mathrm{~s})$ & Scheme 2 \\
& & $0 \sim 0.08 \mathrm{~s}$ & $0 \sim 0.22 \mathrm{~s}$ \\
\hline Mean acceleration $(\mathrm{g})$ & -2.25 & -2.49 & -1.21 \\
\hline
\end{tabular}

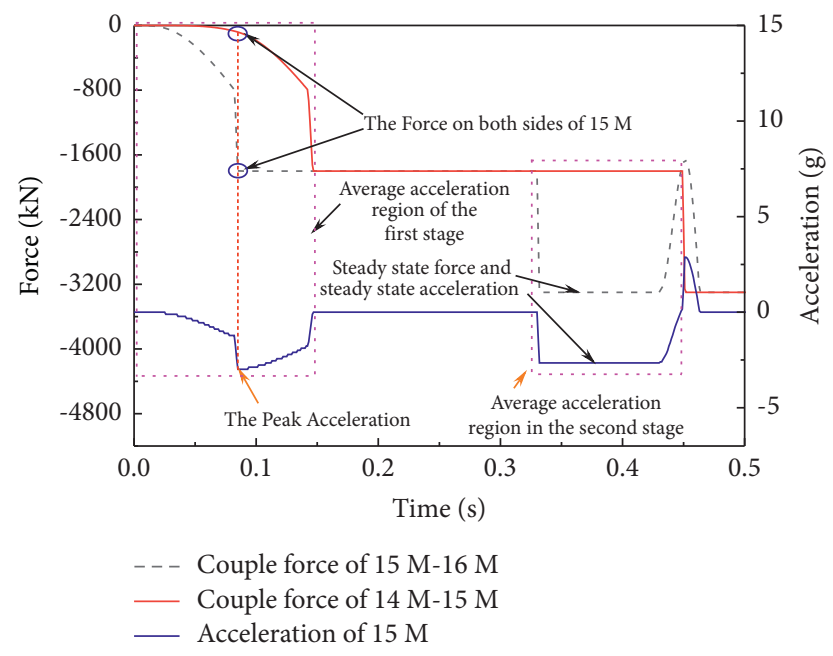

Figure 6: Acceleration curves and interface force at both ends of $15 \mathrm{M}$ car from 0 to $0.5 \mathrm{~s}$. 


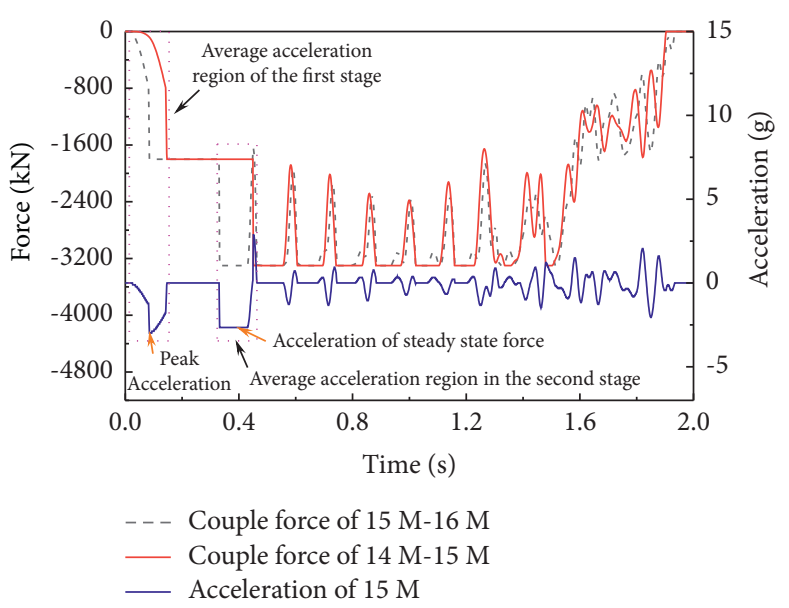

(a)

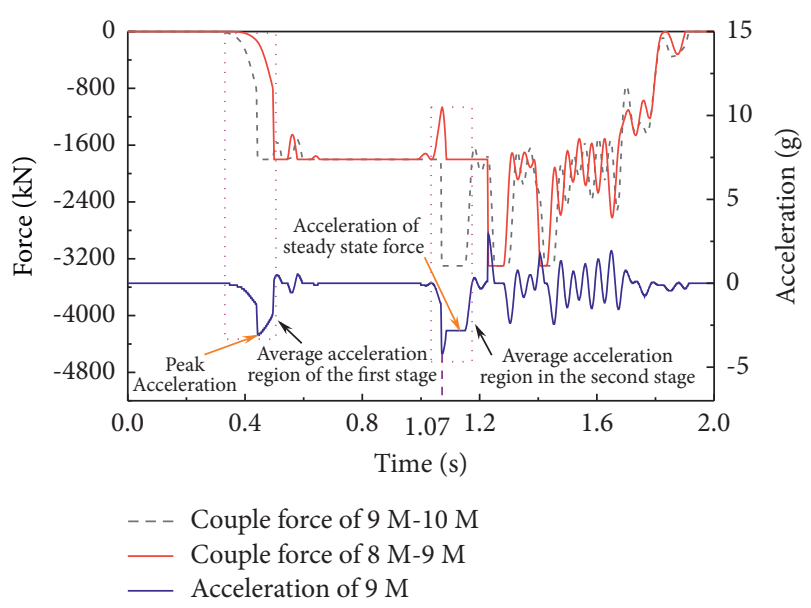

(b)

Figure 7: Comparison curve of coupler force at both ends and acceleration: (a) 15M; (b) 9M.

Considering the energy configuration parameters in scheme 1 (Table 2) as an example, the interfacial force at both ends of the vehicle and the time curve of the car body acceleration during the train collision process are obtained. According to the analysis of the mean-peak ratio in, the $10 \mathrm{M}-16 \mathrm{M}$ cars are mainly observed in stage 2 . In addition, for 16 marshaling train, $8 \mathrm{M}$ and $9 \mathrm{M}$ are intermediate vehicles. Considering that the collision of vehicles close to the collision interface is more severe, $9 \mathrm{M}$ is selected as the intermediate vehicle for analysis. Although the acceleration change process of $16 \mathrm{M}$ vehicle is the same as that of other vehicles, its mean-peak ratio in the first stage is different from that of other vehicles. To avoid particularity, 15M vehicle is selected as a typical representative for analysis in this paper. In summary, we chose cars $9 \mathrm{M}$ and $15 \mathrm{M}$ as representatives for analysis.

4.1. Acceleration Response Analysis of Train Collision. As shown in Figure 7, the area of maximum mean acceleration is composed of two parts: stage 1 and stage 2. Stage 3 represents the process of acceleration oscillation caused by the loading and unloading of interface forces at both ends of the car body during a train collision; the acceleration action time in this process is relatively short. Thus, as long as the mean acceleration of stages 1 and 2 during the longitudinal collision is calculated according to the energy configuration information, the maximum mean acceleration during the train collision can be obtained from the calculation results.

Figure 8 shows the interface force and acceleration curve of the car body of moving train cars $1 \mathrm{M}-7 \mathrm{M}$. It is observed that cars $1 \mathrm{M}-7 \mathrm{M}$ have only the mean acceleration of the first stage; the accelerations of the other stages during the collision are in high-frequency oscillation or are less than the peak acceleration and mean acceleration of the first stage. To unify the calculation formula for mean acceleration, the mean acceleration of $1 \mathrm{M}-9 \mathrm{M}$ moving cars was replaced by the mean acceleration of the first stage in this study. The rationality and feasibility of the replacement are discussed in the next section.

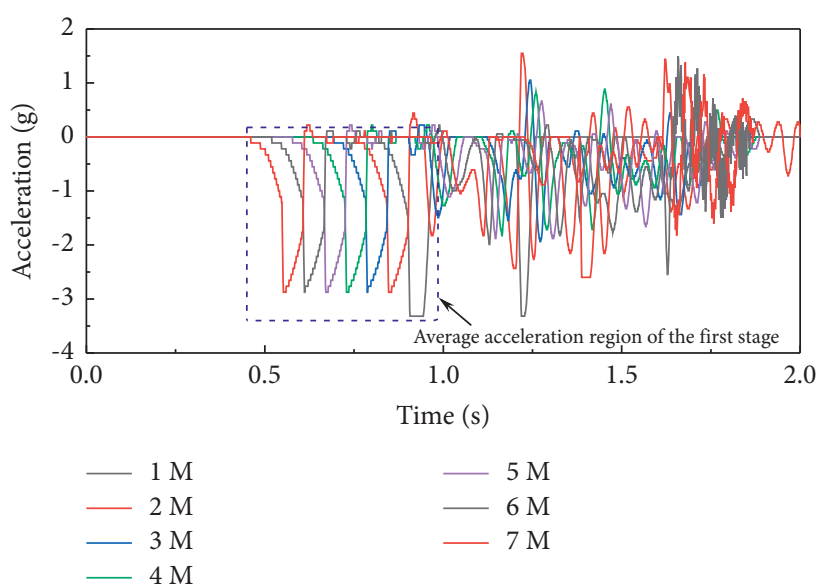

Figure 8: Acceleration-time curve for moving vehicles $1 \mathrm{M}-7 \mathrm{M}$.

\subsection{Mean-Peak Ratio}

4.2.1. Acceleration Calculations for Different Schemes. Based on the initial energy configuration parameters of the train, 12 sets of train energy configuration parameters were formulated based on the Latin hypercube design [45], as shown in Table 4. The process is as follows:

(1) Identify the main energy-absorbing components: the main structures (components) of the train involved in collision energy absorption in this article are the couple collapse tube of head vehicle and middle vehicle, the energy-absorbing device of head vehicle and middle vehicle

(2) Design variable selection: according to the determined main energy-absorbing components, this paper selects 8 parameters as the design variables: the crush stroke and average crushing force (F_H_C, S_H_C, F_I_C, S_I_C, the meaning is shown in Table 4) of the couple collapse tube of head vehicle and middle vehicle, and the crush stroke and average crushing force (F_H_EAD, S_H_EAD, F_I_EAD, 
S_I_EAD) of the energy-absorbing device of head vehicle and middle vehicle.

(3) Determine the selection range of design variables: the change interval of each design variable is as follows: F_H_C $\in[1600,2500]$, S_H_C $\in[500,800]$, F_I_C $\epsilon[1500,2000]$, S_I_C $\epsilon[400,600]$, F_H_EAD $\epsilon$ $[2500,4000], \quad$ S_H_EAD $\epsilon[650,900]$, F_I_EAD $\epsilon$ $[1300,2100]$, S_I_EAD $\in[180,360]$.

(4) Selection of sample points: in Isight's experimental design module, select the Latin hypercube design algorithm, enter the variation interval of each design variable, and generate 12 sets of sample points, as shown in Table 4.

The train collision simulation calculation was conducted using the established longitudinal train collision finite element model. The peak acceleration in each stage of the moving car body structure and the corresponding IMA for each stage during the train collision process were obtained.

Figure 9(a) shows the IMA of stages 1 and 2 for each car body structure for energy configuration schemes 1-10 in Table 4.

From the figure, the following conclusions can be drawn: (1) the overall difference in the IMA for each car body structure in stage 1 is not large; the mean acceleration of $16 \mathrm{M}$ is greater than the IMA of the other car body structures; (2) $10 \mathrm{M}-16 \mathrm{M}$ has the IMA of stage 2 ; cars $7 \mathrm{M}-9 \mathrm{M}$ have the IMA of stage 2 under partial energy allocation schemes, generally not greater than the IMA of the head car body structure; (3) in addition to the acceleration of the car body structure of the head car, the IMA of stage 1 is not greater than the IMA of stage 2; thus, the maximum mean acceleration of car body structure $1 \mathrm{M}-9 \mathrm{M}$ is replaced by the IMA of stage 1 , and the maximum mean acceleration of the train collision does not decrease; (4) for unreasonable energy scheme configurations, the maximum mean acceleration of the head car body is positive; the car body accelerates, but not with an actual train collision energy configuration scheme. From the analysis, it is feasible to replace the mean acceleration of cars $1 \mathrm{M}-9 \mathrm{M}$ with the mean acceleration of stage 1 .

4.2.2. Definition of Mean-Peak Ratio. Figure 9(b) shows the ratio of the improved mean acceleration to the peak acceleration or steady-state force acceleration of each car body structure in stages 1 and 2 (mean-peak ratio, MPR). The calculation formula is defined as

$$
\mathrm{MPR}_{i}=\frac{\mathrm{MA}_{i}}{\mathrm{PA}_{i}} \frac{\mathrm{MA}_{i}}{\mathrm{SSA}_{i}}
$$

where MA represents the mean acceleration of each stage; PA represents the peak acceleration of each stage; SSA represents the steady-state force acceleration of stage 2 .

4.2.3. Statistical Analysis of Data. According to the statistical analysis of the mean-peak ratio coefficient of each vehicle, it is found that, except for the leading vehicle, the median of the mean-peak ratio coefficient in the first stage and the second stage is 0.43 and 0.93 , respectively. The mean-peak ratio coefficient and median of each vehicle are shown in Figure 9(b).

From the data in Figure 9(b), the following conclusions can be drawn: (1) the mean-peak ratio for cars $1 \mathrm{M}-15 \mathrm{M}$ in stage 1 shows a small change concentrated around 0.43; the mean-peak ratio of car $16 \mathrm{M}$ is $0.7 ;(2)$ moving cars $10 \mathrm{M}-16 \mathrm{M}$ all have the improved mean acceleration of stage 2; cars $5 \mathrm{M}-9 \mathrm{M}$ have the improved mean acceleration of stage 2 with partial energy configuration schemes. The mean-peak ratio is less than 0.93 or concentrated around 0.93 and is not obviously greater than the mean-peak ratio of cars $10 \mathrm{M}-16 \mathrm{M}$. With the improved mean acceleration of each car body structure in Figure 9, the maximum mean acceleration of a train collision is generally not generated in cars $5 \mathrm{M}-9 \mathrm{M}$; only the improved mean acceleration of the first stage for cars $1 \mathrm{M}-9 \mathrm{M}$ is reasonable; (3) according to the calculation data in Figure 9(b), the mean-peak ratio of stage 1 of the head car body structure is 0.7 ; the other mean-peak ratios can be replaced with 0.43 ; the mean-peak ratio of stage 2 is 0.93 .

To determine whether 0.43 and 0.93 can replace the mean-peak ratio for other cars, the mean-peak ratios obtained for the ten energy configuration schemes in the figure were statistically analyzed. Based on the data distribution characteristics, a single-sample nonparametric test was used. Nonparametric testing does not depend on the overall distribution type and checks the distribution of the overall parameters or the location of the distribution. It is usually suitable for data testing in small sample spaces, categorical data, and ordinal data. Commonly used nonparametric test methods include the Wilcoxon signed rank test (singlesample test), the Mann-Whitney double independent sample test, and multiple independent sample tests. The data in this study represents a single-sample problem; the singlesample Wilcoxon signed rank test was used [46-48].

The test results at the level of 0.05 are shown in Table 5 . According to the test results, the $p$ values of the first and second stages are 0.84 and 0.28 , respectively, far greater than 0.05 . At the level of 0.05 , the overall median is not significantly different from the test median (0.43 and 0.93). Thus, 0.43 can be used to represent the mean-peak ratio of stage 1 , and 0.93 can be used to represent the mean-peak ratio of stage 2 .

Figure 10 shows the calculation results of the mean-peak ratio at each stage of scheme 11 and scheme 12 in Table 4. In stage 1 , only $14 \mathrm{M}$ and $15 \mathrm{M}$ have a mean-peak ratio greater than 0.43 . In scheme 12 , the mean-peak ratio of other cars is less than 0.43 , and the mean-peak ratio of $16 \mathrm{M}$ is less than 0.7 ; the ratios are not significantly greater than 0.93 in stage 1. Using mean-peak ratios of $0.43,0.7$, and 0.93 to calculate the mean acceleration produces results that are too large; however, from the perspective of safety, the energy allocation scheme is safer. The mean-peak ratio obtained in Figure 9 (b) can be used to check the energy allocation scheme of the train. 


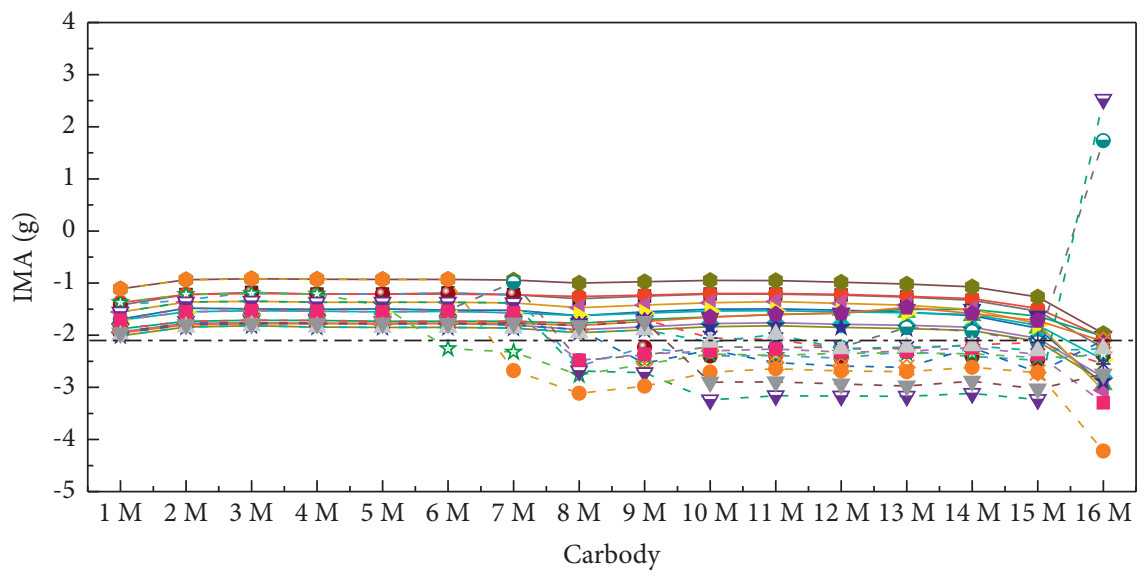

- Scheme1_Stage1

- Scheme2_Stage1

- - Scheme3_Stage1

$\boldsymbol{\nabla}$ Scheme4_Stage1

$\checkmark$ - Scheme5_Stage1

— Scheme6_Stage1

- - Scheme7_Stage1

- - Scheme8_Stage1

* Scheme9_Stage1

- Scheme10_Stage1
- Scheme1_Stage2

- ․ㅡㄴ-Scheme2_Stage2

- - Scheme3_Stage2

- *- Scheme4_Stage2

- Scheme5_Stage2

- $\nabla$ - Scheme6_Stage2

- - Scheme7_Stage2

- - Scheme8_Stage2

- $\Delta$ - Scheme9_Stage2

- $\nabla$ - Scheme10_Stage2

(a)

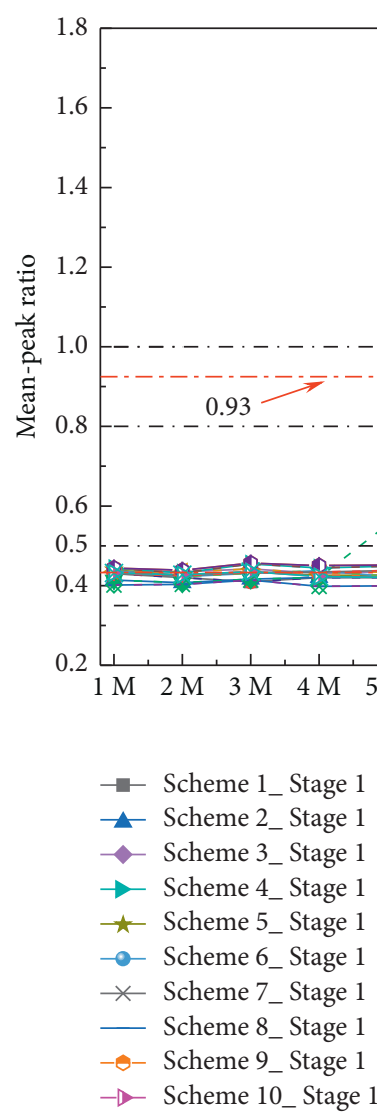

Carbody

- - Scheme 1_Stage 2

- 7 - Scheme 2_Stage 2

- 4. Scheme 3_ Stage 2

- Scheme 4_Stage 2

- - Scheme 5_Stage 2

- +- Scheme 6_Stage 2

- *. Scheme 7_Stage 2

- Scheme 8_Stage 2

- - Scheme 9_Stage 2

- - Scheme 10_Stage 2

(b)

FIgure 9: Mean acceleration and MPR for each stage of car body for schemes 1-10. (a) Mean acceleration. (b) MPR. 
TABLE 4: Energy configuration scheme for multistage energy-absorption system.

\begin{tabular}{|c|c|c|c|c|c|c|c|c|}
\hline \multirow[b]{2}{*}{$\begin{array}{l}\text { Scheme } \\
\text { No }\end{array}$} & \multicolumn{2}{|c|}{$\begin{array}{l}\text { Energy-absorbing device of head } \\
\text { vehicle }\end{array}$} & \multicolumn{2}{|c|}{$\begin{array}{l}\text { Energy absorbing device of } \\
\text { intermediate vehicle }\end{array}$} & \multicolumn{2}{|c|}{$\begin{array}{l}\text { Couple collapse tube of } \\
\text { head vehicle }\end{array}$} & \multicolumn{2}{|c|}{$\begin{array}{l}\text { Couple collapse tube of } \\
\text { intermediate vehicle }\end{array}$} \\
\hline & $\begin{array}{c}\text { Average } \\
\text { crushing force } \\
\text { (F_H_EAD) } \\
(\mathrm{kN})\end{array}$ & $\begin{array}{l}\text { Crush stroke } \\
(\text { S_H_EAD) } \\
(\mathrm{mm})\end{array}$ & $\begin{array}{c}\text { Average } \\
\text { crushing force } \\
(\text { F_I_EAD) } \\
(\mathrm{kN})\end{array}$ & $\begin{array}{c}\text { Crush stroke } \\
\text { (S_I_EAD) } \\
(\mathrm{mm})\end{array}$ & $\begin{array}{c}\text { Average } \\
\text { crushing } \\
\text { force } \\
(\text { F_H_C }) \\
(\mathrm{kN})\end{array}$ & $\begin{array}{c}\text { Crush } \\
\text { stroke } \\
\left(\mathrm{S} \_\mathrm{H} \_\mathrm{C}\right) \\
(\mathrm{mm})\end{array}$ & 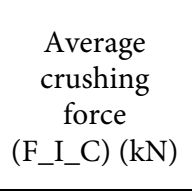 & $\begin{array}{c}\text { Crush } \\
\text { stroke } \\
(\text { S_I_C) } \\
(\mathrm{mm})\end{array}$ \\
\hline 1 & 3100.00 & 750.00 & 1500.00 & 210.00 & 1800.00 & 600.00 & 1800.00 & 438.00 \\
\hline 2 & 3100.00 & 695.45 & 1500.00 & 317.78 & 1641.41 & 759.60 & 1800.00 & 424.24 \\
\hline 3 & 3666.67 & 745.96 & 1351.52 & 308.89 & 2398.99 & 767.17 & 2085.86 & 474.75 \\
\hline 4 & 3787.88 & 814.14 & 1361.62 & 242.22 & 1631.31 & 557.58 & 2358.59 & 553.54 \\
\hline 5 & 3530.30 & 761.11 & 1634.34 & 348.89 & 2247.48 & 800.00 & 2378.79 & 577.78 \\
\hline 6 & 3636.36 & 801.52 & 2018.18 & 337.78 & 2489.90 & 673.74 & 1944.44 & 587.88 \\
\hline 7 & 3969.70 & 751.01 & 1341.41 & 353.33 & 1964.65 & 736.87 & 2146.47 & 490.91 \\
\hline 8 & 3984.85 & 859.60 & 1654.55 & 226.67 & 1601.01 & 635.86 & 1500.00 & 529.29 \\
\hline 9 & 3712.12 & 872.22 & 1371.72 & 262.22 & 2308.08 & 729.29 & 2449.50 & 539.39 \\
\hline 10 & 2878.79 & 740.91 & 1856.57 & 297.78 & 1691.92 & 724.24 & 2479.80 & 557.58 \\
\hline 11 & 3227.27 & 773.74 & 2068.69 & 351.11 & 2368.69 & 777.27 & 1904.04 & 416.16 \\
\hline 12 & 2500.00 & 816.67 & 1593.94 & 191.11 & 2156.57 & 676.26 & 1984.85 & 547.47 \\
\hline
\end{tabular}

Table 5: One-sample Wilcoxon signed rank test.

\begin{tabular}{lccc}
\hline & Index & The first stage & The second stage \\
\hline & Min & 0.35 & 0.78 \\
& Q1 & 0.41 & 0.91 \\
Median & Q3 & 0.43 & 0.93 \\
& Max & 0.44 & 0.945 \\
& $p$ value & 0.54 & 1 \\
\hline
\end{tabular}

Note: Q1 represents the quartile, and Q3 represents the third quartile.

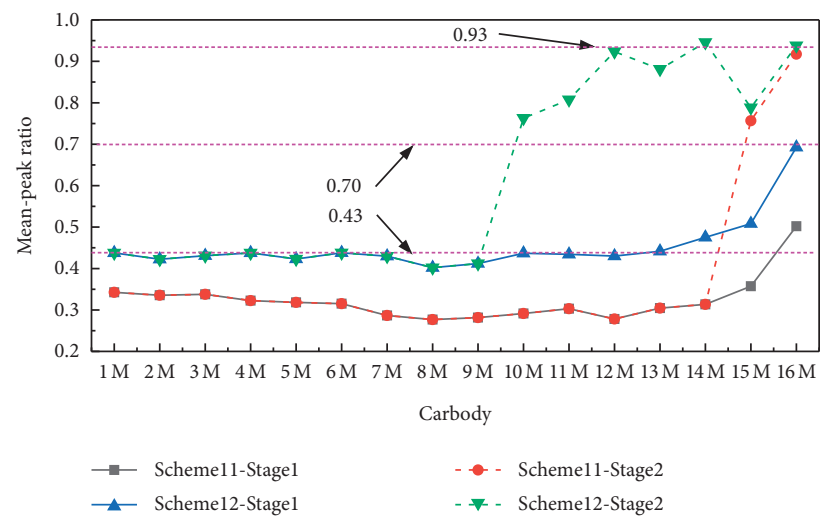

FIgURE 10: Mean-peak ratio of car body structure for scheme 11 and scheme 12 .

\section{Calculation Method for Maximum Mean Acceleration of Longitudinal Train Collision}

The mean-peak ratios of stages 1 and 2 were obtained according to the analysis. As long as the peak acceleration and steady-state force acceleration of each stage are calculated and multiplied by the corresponding mean-peak ratio, the mean acceleration of each car body can be obtained for a given energy configuration scheme. The maximum acceleration of each vehicle is the maximum mean acceleration in a train collision; the collision resistance of the one-dimensional energy configuration scheme of the train can be checked without traditional complex numerical calculations.

\subsection{Calculation Formula for Maximum Mean Acceleration}

5.1.1. Calculation of Mean Acceleration in Stage 1. Figure 6 shows a typical acceleration curve for a car body and the interface force at both ends from 0 to $0.5 \mathrm{~s}(15 \mathrm{M}$ car, for example). From the curve, the peak acceleration point of 
stage 1 occurs when the front-end coupler of the $15 \mathrm{M}$ car starts to work, and the rear end coupler is in the buffer compression stage. The formula for calculating the peak acceleration for each car in the first stage is expressed as

$$
a_{P_{-} i_{-} 1}=\frac{F_{i_{-} c}-F_{i-b}}{m_{i}},
$$

where $a_{P_{-} i_{-} 1}$ represents the peak acceleration of the $i^{\text {th }}$ vehicle in stage $1 ; F_{i_{-}}$represents the crushing force of the collapse tube of the front-end coupler of the $i^{\text {th }}$ vehicle; $F_{i_{-} b}$ represents the compression force of the rear end coupler draft gear of the $i^{\text {th }}$ vehicle, $1 \leq i \leq 16$.

As shown in Figure 6, $F_{i_{-} b} \ll F_{i_{-}}$; the compression force of the coupler draft gear can be ignored, and the peak acceleration of the $i^{\text {th }}$ vehicle in stage 1 is calculated as

$$
a_{P_{-} i_{-} 1}=\frac{F_{i_{-}}}{m_{i}} .
$$

The calculation formula for the mean acceleration of the $i^{\text {th }}$ vehicle in stage 1 is expressed as

$$
\mathrm{MA}_{i_{-} 1}=\gamma a_{P_{-} i_{-} 1}=\gamma \frac{F_{i_{-} c}}{m_{i}},
$$

where $\mathrm{MA}_{i_{-} 1}$ represents the mean acceleration of the $i^{\text {th }}$ vehicle in stage 1; $\gamma$ is the mean-peak ratio of stage 1 ; the head vehicle is set to 0.7 , and the other vehicles are set to 0.43 .

5.1.2. Calculation of Mean Acceleration of Stage 2. Calculation of the mean acceleration of stage 2 is more complicated than calculation of the mean acceleration of stage 1 and is conducted in two parts:

(1) Mean Acceleration of Head Vehicle. From Figure 1(a), the 16M-16S interface contains multilevel energy-absorbing structures such as coupler draft gears, main energy-absorbing devices, and anticlimbing devices that are more complicated than at the end of the intermediate vehicle. The mechanical properties of the energy-absorbing structures at both ends are different for different energy allocation schemes, resulting in different time periods, positions, and sequences of the steady-state force acceleration of the head vehicle in stage 2. For example, for schemes 1 and 2 (Table 6), the steady-state force of the head vehicle in stage 2 is the crushing force of the energy-absorbing device of the head vehicle minus the middle coupler force; however, for scheme 3 , the steady-state force of stage 2 of the head vehicle is the sum of the crushing forces of the energy-absorbing structure at the interface of the intermediate vehicle (including the crushing force of the coupler collapse tube and the energyabsorbing structure) minus the crushing force of the coupler collapse tube of the head car.

The focus of this study is to provide a general method for calculating the maximum mean acceleration of each car according to the train energy configuration scheme without complex numerical calculations. The trigger time and determination method of the steady-state force in stage 2 pertain to crash energy management, which is outside the scope of this study. It is assumed that the steady-state force is known to focus on verifying the accuracy of the method from the data in Figure 9.

Based on the assumptions, the calculation formula for the steady-state force acceleration of the head vehicle in stage 2 is expressed as

$$
a_{S S_{-} h_{-} 2}=\frac{F_{S S}}{m_{16} M},
$$

where $a_{S S_{-} 2}$ represents the steady-state force acceleration of the head vehicle in stage 2; $F_{S S}$ represents the steady-state force of the head vehicle in stage 2 , according to the values of each scheme shown in Table 6; $m_{16 M}$ represents the structural mass of the head vehicle.

The formula for calculating the mean acceleration of the head vehicle in stage 2 is

$$
\begin{aligned}
\mathrm{MA}_{S S_{-} h_{-}-2} & =\eta a_{s s_{-} h_{-} 2}, \\
& =\eta \frac{F_{s s}}{m_{16 M}},
\end{aligned}
$$

where $\mathrm{MA}_{S S_{-} h_{-} 2}$ represents the mean acceleration of the head vehicle in stage $2 ; \eta$ is the mean-peak ratio of stage 2 , which is 0.93 .

(2) Mean Acceleration of Intermediate Vehicle. Compared with the energy-absorbing structure at both ends of the head vehicle, the mechanical properties of the coupler and the energy-absorbing device at both ends of the intermediate vehicle are the same.

From the curves of the interface force at both ends of the $15 \mathrm{M}$ car and the acceleration of the car body in Figure 6, the steady-state force acceleration of the intermediate car in stage 2 is caused by the hysteresis of the energy-absorbing structure at both ends of the vehicle due to train marshaling. The energy-absorbing structure at the front end was crushed in energy absorption; the energy-absorbing structure at the rear end has not yet absorbed energy.

Thus, when the mean acceleration in stage 2 is reached, the resultant force at both ends of the vehicle is equal to the difference between the average crushing force of the energyabsorbing device of the intermediate vehicle and the average crushing force of the coupler collapse tube. The calculation formula for the steady-state force acceleration of the intermediate vehicle in stage 2 is expressed as

$$
a_{s s_{-} i_{-} 2}=\frac{F_{i_{-} \text {ead } \_m}}{m_{i}},
$$

where $a_{s s_{-} i_{-2}}$ represents the steady-state force acceleration of the $i^{\text {th }}$ vehicle in stage 2; $F_{i \text { ead_m } m}$ represents the average crushing force of the energy-absorbing device at the interface of the intermediate vehicle; $1 \leq i<16$.

The calculation formula for the mean acceleration of the $i^{\text {th }}$ vehicle in stage 2 is expressed as

$$
\mathrm{MA}_{i \_m \_2}=\mu \frac{F_{i_{-} \text {ead } \_m}}{m_{i}},
$$


TABLE 6: Steady-state force $F_{S S}$ in stage 2 for leading car in each scheme.

\begin{tabular}{|c|c|c|}
\hline Scheme & $\begin{array}{l}\text { Steady-state force } \\
(\mathrm{kN})\end{array}$ & Explanation \\
\hline 1 & 1300.00 & Average crushing force of energy-absorbing device of head car minus middle coupler force \\
\hline 2 & 1300.00 & Average crushing force of energy-absorbing device of head car minus middle coupler force \\
\hline 3 & 1038.38 & The resultant force of two-end minus the coupler force of head car \\
\hline 4 & 1429.29 & Average crushing force of energy-absorbing device of head car minus middle coupler force \\
\hline 5 & 1151.52 & Average crushing force of energy-absorbing device of head car minus middle coupler force \\
\hline 6 & 1472.73 & The resultant force of two-end minus the coupler force of head car \\
\hline 7 & 1823.23 & Average crushing force of energy-absorbing device of head car minus middle coupler force \\
\hline 8 & 2484.85 & Average crushing force of energy-absorbing device of head car minus middle coupler force \\
\hline 9 & 1262.63 & Average crushing force of energy-absorbing device of head car minus middle coupler force \\
\hline 10 & 1663.634 & $\begin{array}{l}\text { The crushing force of the high energy crushing zone of the car body minus the resultant force of the two- } \\
\text { end interface }\end{array}$ \\
\hline
\end{tabular}

where $\mathrm{MA}_{i_{-} 2}$ represents the mean acceleration of the $i^{\text {th }}$ vehicle in stage $2 ; \mu$ is the mean-peak ratio of stage 2 . According to Table $5, \eta=\mu=0.93$.

(3) Calculation of Maximum Mean Acceleration. According to the crashworthiness standard EN 15227:2020, the maximum mean acceleration is the main safety index for the longitudinal collision assessment of the train, and the maximum mean acceleration of a train collision is the maximum mean acceleration of each vehicle during the collision. According to equations (5), (7) and (9), the maximum mean acceleration during the longitudinal collision of a train can be obtained; the calculation formula is expressed as

$$
\mathrm{MA}_{\max }=\max \left[\mathrm{MA}_{i_{-} 1}, \mathrm{MA}_{s s_{-} h_{-} 2}, \mathrm{MA}_{i_{-} m_{-} 2}\right] \text {, }
$$

where $\mathrm{MA}_{\max }$ is the maximum mean acceleration during the train collision.

5.2. Mean Acceleration Difference Test. It is observed from the calculation results that the maximum mean acceleration is generally generated in stage 2 . Thus, to verify the correctness of the theoretical calculation formula, and demonstrate that there is a small difference between the theoretical calculation result and the numerical calculation result, the mean acceleration calculated by the theoretical formula and the numerical simulation in Figure 11 are compared, using the Kruskal-Wallis ANOVA multisample independent nonparametric test for difference analysis; the results are shown in Table 7.

Numerical simulation (NS) and theoretical calculation (TC) in Table 7 , respectively, represent the acceleration calculated by the longitudinal train collision dynamics model simulation calculation (traditional method) and theoretical calculation formula Result. Min, Q1, Median, Q3 and Max, respectively, represent the minimum, quartile, median, three-quarter, and maximum digits of the vehicle body acceleration under the same energy configuration scheme. It can be seen from the data in the table that there is no significant difference between the calculation result of the calculation formula and the calculation result of the traditional acceleration calculation method.

Except for the p-value in scheme 7, which is less than 0.05 , the difference between the theoretical calculation results and the numerical simulation calculation results for the other schemes is greater than 0.05. The minimum, quartile, median, and third quartile differ slightly from the numerical simulation calculation; the mean acceleration of each vehicle in stage 2 using the two calculation methods is not significantly different at the level of 0.05 .

The $p$ value for scheme 7 is 0.02 , and there is a difference between the two groups of data. However, from the minimum value, quartile, median, and other parameters in the test results in Figure 11 and Table 7, and the error of the two groups of data in Table 8 , there is no significant difference between the theoretical calculation results and the numerical calculation results; the maximum error of the mean acceleration for the two groups of data is $3.57 \%$.

The calculation results can replace the numerical simulation results in engineering practice.

5.3. Summary of Calculation Methods for Maximum Mean Acceleration. Through nonparametric data testing and analysis, the correctness and reliability of the theoretical calculation results were verified. Without numerical simulation, the theoretical calculation formula can be used to calculate the maximum mean acceleration of the car body during a longitudinal train collision. The calculation process is illustrated in Figure 12.

The traditional maximum mean acceleration calculation method requires numerical simulation based on the existing energy configuration scheme and train information to obtain the acceleration time history of each car body structure during the train collision. Calculating the mean acceleration of each time period separately, and then taking the maximum value, the calculation process is cumbersome. The developed method does not require numerical calculation. It only needs to calculate the maximum mean acceleration of each vehicle according to the energy configuration scheme and train information, and the calculation process is simple. 


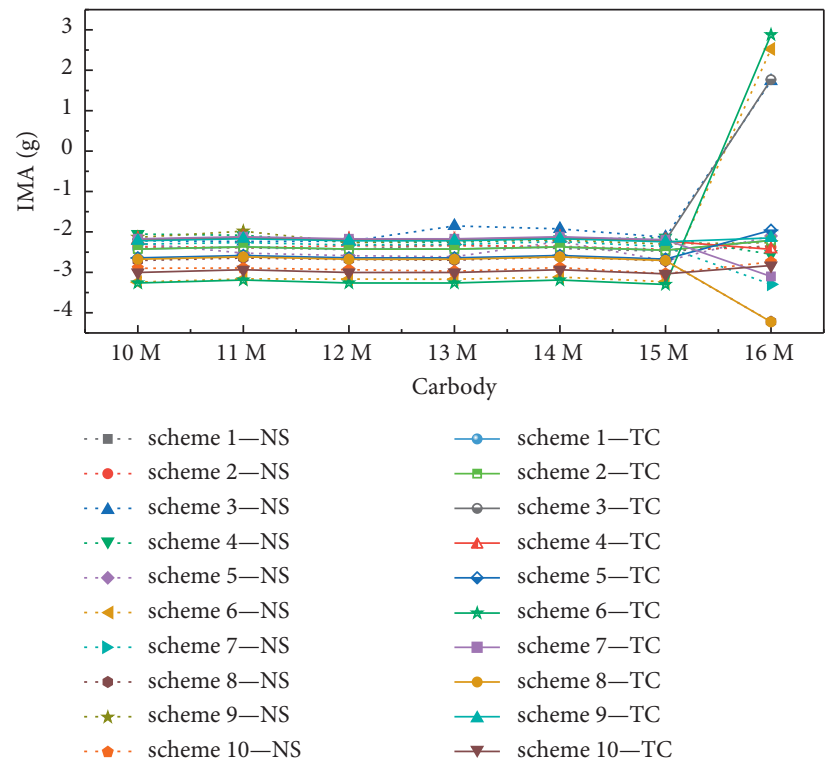

FIGURE 11: Improved mean acceleration of car body structure in stage 2 for numerical simulation and theoretical calculation. Note. Numerical simulation (NS) represents the acceleration result calculated in the one-dimensional train collision dynamics model simulation; theoretical calculation (TC) represents the acceleration result calculated by the theoretical calculation formula.

TAвLE 7: Kruskal-Wallis ANOVA multisample independent nonparametric test.

\begin{tabular}{|c|c|c|c|c|c|c|c|}
\hline Scheme & Calculation method & Min & Q1 & Median & Q3 & $\operatorname{Max}$ & $p$ value \\
\hline 1 & $\begin{array}{l}\text { NS } \\
\text { TC }\end{array}$ & $\begin{array}{l}-2.48 \\
-2.45\end{array}$ & $\begin{array}{l}-2.44 \\
-2.43\end{array}$ & $\begin{array}{l}-2.40 \\
-2.44\end{array}$ & $\begin{array}{l}-2.35 \\
-2.37\end{array}$ & $\begin{array}{l}-2.31 \\
-2.21\end{array}$ & 0.95 \\
\hline 2 & $\begin{array}{l}\text { NS } \\
\text { TC }\end{array}$ & $\begin{array}{r}-2.43 \\
-2.45 \\
\end{array}$ & $\begin{array}{l}-2.39 \\
-2.43 \\
\end{array}$ & $\begin{array}{l}-2.36 \\
-2.43 \\
\end{array}$ & $\begin{array}{l}-2.34 \\
-2.37 \\
\end{array}$ & $\begin{array}{l}-2.34 \\
-2.21 \\
\end{array}$ & 0.27 \\
\hline 3 & $\begin{array}{l}\text { NS } \\
\text { TC }\end{array}$ & $\begin{array}{l}-2.23 \\
-2.21 \\
\end{array}$ & $\begin{array}{r}-2.23 \\
-2.19 \\
\end{array}$ & $\begin{array}{l}-2.13 \\
-2.19 \\
\end{array}$ & $\begin{array}{c}-1.85 \\
-2.134 \\
\end{array}$ & $\begin{array}{l}1.73 \\
1.77 \\
\end{array}$ & 0.95 \\
\hline 4 & $\begin{array}{l}\text { NS } \\
\text { TC }\end{array}$ & $\begin{array}{l}-2.55 \\
-2.43 \\
\end{array}$ & $\begin{array}{l}-2.26 \\
-2.23 \\
\end{array}$ & $\begin{array}{l}-2.18 \\
-2.20 \\
\end{array}$ & $\begin{array}{l}-2.08 \\
-2.15 \\
\end{array}$ & $\begin{array}{l}-2.05 \\
-2.15 \\
\end{array}$ & 0.65 \\
\hline 5 & $\begin{array}{l}\text { NS } \\
\text { TC } \\
\end{array}$ & $\begin{array}{l}-2.72 \\
-2.67 \\
\end{array}$ & $\begin{array}{l}-2.62 \\
-2.64 \\
\end{array}$ & $\begin{array}{l}-2.52 \\
-2.64\end{array}$ & $\begin{array}{l}-2.23 \\
-2.58 \\
\end{array}$ & $\begin{array}{r}-2.10 \\
-1.96 \\
\end{array}$ & 0.34 \\
\hline 6 & $\begin{array}{l}\text { NS } \\
\text { TC }\end{array}$ & $\begin{array}{l}-3.24 \\
-3.30 \\
\end{array}$ & $\begin{array}{l}-3.23 \\
-3.26 \\
\end{array}$ & $\begin{array}{l}-3.17 \\
-3.26 \\
\end{array}$ & $\begin{array}{l}-3.11 \\
-3.19 \\
\end{array}$ & $\begin{array}{l}2.52 \\
2.88 \\
\end{array}$ & 0.08 \\
\hline 7 & $\begin{array}{l}\text { NS } \\
\text { TC } \\
\end{array}$ & $\begin{array}{r}-3.30 \\
-3.10 \\
\end{array}$ & $\begin{array}{l}-2.37 \\
-2.19 \\
\end{array}$ & $\begin{array}{l}-2.31 \\
-2.17 \\
\end{array}$ & $\begin{array}{l}-2.26 \\
-2.12 \\
\end{array}$ & $\begin{array}{r}-2.23 \\
-2.12 \\
\end{array}$ & 0.02 \\
\hline 8 & $\begin{array}{l}\text { NS } \\
\text { TC }\end{array}$ & $\begin{array}{l}-4.22 \\
-4.23\end{array}$ & $\begin{array}{l}-2.72 \\
-2.71\end{array}$ & $\begin{array}{l}-2.70 \\
-2.68\end{array}$ & $\begin{array}{l}-2.64 \\
-2.62\end{array}$ & $\begin{array}{l}-2.62 \\
-2.62\end{array}$ & 0.33 \\
\hline 9 & $\begin{array}{l}\text { NS } \\
\text { TC }\end{array}$ & $\begin{array}{r}-2.23 \\
-2.24 \\
\end{array}$ & $\begin{array}{r}-2.26 \\
-2.22 \\
\end{array}$ & $\begin{array}{l}-2.23 \\
-2.21 \\
\end{array}$ & $\begin{array}{l}-2.13 \\
-2.17 \\
\end{array}$ & $\begin{array}{r}-1.98 \\
-2.15 \\
\end{array}$ & 0.48 \\
\hline 10 & $\begin{array}{l}\text { NS } \\
\text { TC }\end{array}$ & $\begin{array}{r}-3.03 \\
-3.04\end{array}$ & $\begin{array}{l}-2.97 \\
-3.00\end{array}$ & $\begin{array}{l}-2.90 \\
-3.00\end{array}$ & $\begin{array}{l}-2.88 \\
-2.94\end{array}$ & $\begin{array}{c}-2.7 \\
-2.83\end{array}$ & 0.22 \\
\hline
\end{tabular}

TABLE 8: Mean acceleration error of two methods for scheme 7.

\begin{tabular}{lccc}
\hline Vehicle number & NS $(\mathrm{g})$ & TC $(\mathrm{g})$ & Error $(\%)$ \\
\hline $10 \mathrm{M}$ & -2.90 & -3.00 & 3.57 \\
$11 \mathrm{M}$ & -2.89 & -2.94 & 1.39 \\
$12 \mathrm{M}$ & -2.94 & -3.00 & 2.24 \\
$13 \mathrm{M}$ & -2.97 & -3.00 & 1.01 \\
$14 \mathrm{M}$ & -2.88 & -2.94 & 1.83 \\
$15 \mathrm{M}$ & -3.03 & -3.04 & 0.2 \\
$16 \mathrm{M}$ & -2.75 & -2.83 & 3.09 \\
\hline
\end{tabular}




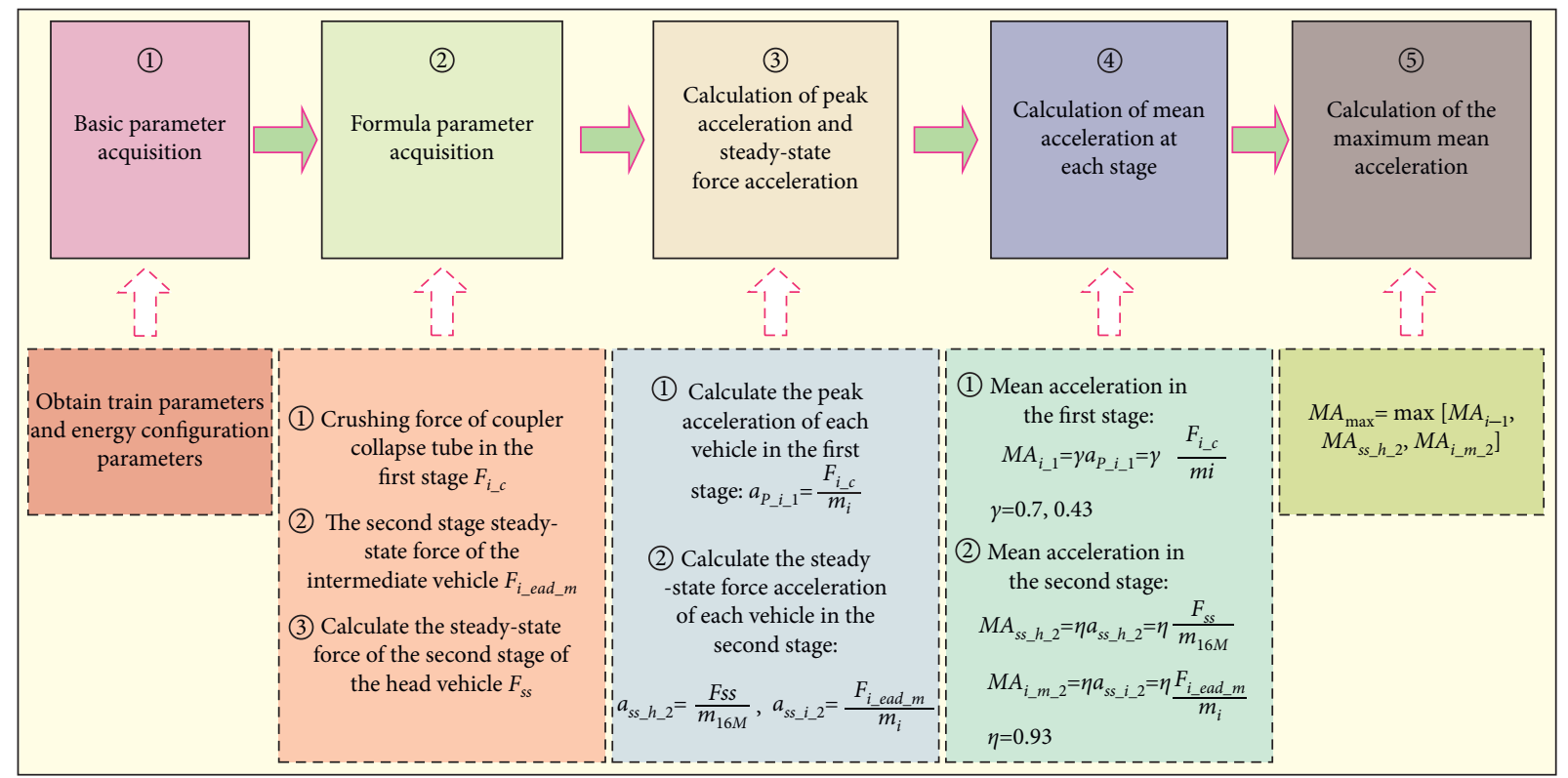

FIGURE 12: Calculation process for maximum mean acceleration.

\section{Conclusion}

Through analysis of the acceleration and interface force curves of the car body structure during a longitudinal train collision, the acceleration change characteristics of the car body structure were summarized, the calculation formula for the maximum mean acceleration of a longitudinal train collision was established, and the correctness of the theoretical empirical formula was verified through comparison with the numerical simulation data.

(1) When using the longitudinal train collision dynamics model to calculate the acceleration of the train collision energy configuration scheme, the maximum mean acceleration is generally generated in two stages. In stage 1, the couplers at both ends of the vehicle act independently; in stage 2 , the energyabsorption device of the head car or the interface of the intermediate car is crushed in energy absorption, and the maximum of the two stages is the maximum mean acceleration of the train collision.

(2) Through analysis of the time-history characteristics of the car body acceleration with different energy configuration schemes, the relationship between the mean acceleration and the peak acceleration or steady-state force acceleration at each stage was obtained, and the MPR parameter was defined. In stage 1 , the MPR of the head vehicle was 0.7 , and the MPR of the intermediate vehicle was 0.43 ; in stage 2, the MPR of each vehicle was 0.93 .

(3) By studying the numerical range of the MPA in each stage, an empirical formula for calculating the maximum mean acceleration of longitudinal train collisions was established. The Kruskal-Wallis
ANOVA multisample independent nonparametric test results indicate that there is no significant difference between the theoretical calculation results and the numerical calculation results; the theoretical calculation formula can be used to calculate the maximum mean acceleration of the train.

The calculation method for the maximum mean acceleration of a longitudinal train collision proposed in this study has a certain application value. The mean acceleration of the car body in an energy allocation scheme can be evaluated without numerical calculation to provide theoretical guidance for the energy allocation phase of the train crashworthiness design, greatly reducing the preliminary design cost and design cycle. However, this study does not consider the trigger time and determination method for the steady-state force of the head vehicle in stage 2 pertaining to train crash energy management. Subsequent research can also verify the reliability of the method proposed in this study and improve the theoretical system of train crash energy management. In addition, taking 16 marshalled train as an example, the acceleration time history of the car body structure during the collision process is analyzed in detail, the mean-peak ratio coefficient of each vehicle is obtained, and a new method for calculating the maximum mean acceleration of longitudinal train collision is proposed. For trains with different marshaling forms, the mean peak to ratio coefficient is different; however, the method proposed in this paper has general applicability.

\section{Data Availability}

The data used to support the findings of this study are included within the article. 


\section{Conflicts of Interest}

The authors declare no potential conflicts of interest with respect to the research, authorship, and/or publication of this article.

\section{Acknowledgments}

This study was supported by the National Natural Science Foundation of China (52172409).

\section{References}

[1] A. Scholes and J. H. Lewis, "Development of crashworthiness for railway vehicle structures," Proceedings of the Institution of Mechanical Engineers - Part F: Journal of Rail and Rapid Transit, vol. 207, no. 16, pp. 1-16, 1993.

[2] British Standards Institution, Structural Requirements for Railway Vehicles: GM/RT 2100, Safety \& Standards Directorate, Railtrack PLC, London, England, 2000.

[3] J. H. Lewis, "Review of crashworthiness work undertaken by BR research 1984-1996,” ResearchReport RRSTR-96-039, UK British Rail, Derby, England, 1996.

[4] Safetram, Passive Safety of Tramways for Europe, European Communication, Denmark, England, 2004.

[5] SAFE INTERIORS, Train Interior Passive Safety for Europe, SAFE INTERIORS, Brussels, Belgium, 2010.

[6] A. Sutton, "The development of rail vehicle crashworthiness," Proceedings of the Institution of Mechanical Engineers - Part F: Journal of Rail and Rapid Transit, vol. 216, no. 2, pp. 97-108, 2002.

[7] A. Erskine, Literature Review of Rail Vehicle Structural Crashworthiness, Rail Safety and Standards Board, London, England, 2004.

[8] M. Carolan, M. Muhlanger, B. Perlman, and D. Tyrell, "Occupied volume integrity testing: elastic test results and analyses," in Proceedings of the ASME 2011 Rail Transportation Division Fall Technical Conference, September 2011.

[9] D. Tyrell, K. Jacobsen, D. Parent, and B. Perlman, "Preparations for a train-to-train impact test of crash-energy management passenger rail equipment," in Proceedings of the 2005 Asme/Ieee Joint Rail Conference: Research and Testing For Industry Advancement, pp. 107-116, Amer Soc Mechanical Engineers, Pueblo, CO, USA, March 2005.

[10] K. Jacobsen, D. Tyrell, and B. Perlman, "Impact test of a crashenergy management passenger rail car," in Proceedings of the ASME/IEEE Joint Rail Conference, Drawin, Australia, June 2004.

[11] Federal Railroad Administration, Passenger Equipment Safety Standards:49 CFR Part 229, Transportation, 1997.

[12] K. Jacobsen, D. Tyrell, K. Severson, and E. Martinez, Crash Energy Management: One- and Two-Car Passenger Rail Impact Tests Summary of Structural and Occupant Test Results, U.S. Department of Transportation John A. Volpe National Transportation Systems Center, Washington, DC, USA, 2016.

[13] G. Lu, "Collision behaviour of crashworthy vehicles in rakes," Proceedings of the Institution of Mechanical Engineers - Part F: Journal of Rail and Rapid Transit, vol. 213, no. 3, pp. 143-160, 1999.

[14] T. Zhu, S. Xiao, C. Lei et al., "Rail vehicle crashworthiness based on collision energy management: an overview," International Journal of Reality Therapy, vol. 9, no. 2, pp. 101-131, 2020.
[15] P. Xu, S. Lu, K. Yan, and S. Yao, "Energy absorption design study of subway vehicles based on a scaled equivalent model test," Proceedings of the Institution of Mechanical Engineers Part F: Journal of Rail and Rapid Transit, vol. 233, no. 1, pp. 3-15, 2019.

[16] S. H. Jing, K. B. Yan, S. S. Lu et al., "Research on energy absorption elements platform force design of high speed train collision," Journal of Railway Science and Engineering, vol. 16, no. 6, pp. 1384-1390, 2019.

[17] B. Liu, S. N. Xiao, B. Yang, T. Zhu, and G. W. Yang, "Study on impacts of energy absorbing devices on train collision energy absorption," Electric Drive for Locomotives, vol. 39, no. 5, pp. 29-33, 2019.

[18] J. F. Milho, J. A. C. Ambrósio, and M. F. O. S. Pereira, "Design of train crash experimental tests by optimization procedures," International Journal of Crashworthiness, vol. 9, no. 5, pp. 483-493, 2004.

[19] S. N. Xiao, Z. X. Zhang, G. W. Yang et al., "Simulation method for couplers and buffers in train collision calculations," Journal of Southwest Jiaotong University, vol. 49, no. 5, pp. 831-836, 2014.

[20] T. Zhu, B. Z. Yang, C. Yang, S. N. Xiao, G. W. Yang, and B. Yang, "The mechanism for the coupler and draft gear and its influence on safety during a train collision," Vehicle System Dynamics, vol. 56, no. 9, pp. 1375-1393, 2018.

[21] R. X. Qin, J. X. Zhou, and B. Z. Chen, "One-dimensional train collision model based on flexible element and parameters calibration," Journal of the China Railway Society, vol. 41, no. 11, pp. 58-64, 2019.

[22] R. Li, P. Xu, Y. Peng, and Y.-q. Xie, "Scaled tests and numerical simulations of rail vehicle collisions for various train sets," Proceedings of the Institution of Mechanical Engineers Part F: Journal of Rail and Rapid Transit, vol. 230, no. 6, pp. 1590-1600, 2016.

[23] S. Xie, H. Li, C. Yang, and S. Yao, "Crashworthiness optimisation of a composite energy-absorbing structure for subway vehicles based on hybrid particle swarm optimisation," Structural and Multidisciplinary Optimization, vol. 58, no. 5, pp. 2291-2308, 2018.

[24] S. Xie, H. Li, W. Yang, and N. Wang, "Crashworthiness optimisation of a composite energy-absorbing structure for railway vehicles," Structural and Multidisciplinary Optimization, vol. 57, no. 4, pp. 1793-1807, 2018.

[25] S. Xie, N. Wang, W. Yang, and H. Li, "Energy absorption performance of thin-walled metal plate due to upheaval deformation based on experiments and numerical simulation," Thin-Walled Structures, vol. 131, pp. 258-273, 2018.

[26] W. Ma, Z. Li, and S. Xie, "Crashworthiness analysis of thinwalled bio-inspired multi-cell corrugated tubes under quasistatic axial loading," Engineering Structures, vol. 204, Article ID 110069, 2020.

[27] W. Ma, S. Xie, and Z. Li, "Mechanical performance of bioinspired corrugated tubes with varying vertex configurations," International Journal of Mechanical Sciences, vol. 172, Article ID 105399, 2020.

[28] G. Guangjun, "The energy distribution of a train impact process based on the active-passive energy-absorption method," Transportation Safety and Environment, vol. 1, no. 1, pp. 54-67, 2019.

[29] G. Lu, "Energy absorption requirement for crashworthy vehicles," Proceedings of the Institution of Mechanical Engineers Part F: Journal of Rail and Rapid Transit, vol. 216, no. 1, pp. 31-39, 2002. 
[30] H. Shao, P. Xu, S. Yao, Y. Peng, R. Li, and S. Zhao, "Improved multibody dynamics for investigating energy dissipation in train collisions based on scaling laws," Shock and Vibration, vol. 2016, pp. 1-11, 2016.

[31] B. Stuart, "Summary report on dynamic behavior of the whole train in collisions and the improvement of the crashworthiness," Foreign Rolling Stock, vol. 54, no. 5, pp. 1-7, 2017.

[32] B. J. Wang, K. B. Yan, S. S. Lu, H. F. Zhu, and S. G. Yao, "Energy absorption design of metro train based on multibody dynamics," Journal of Railway Science and Engineering, vol. 15, no. 4, pp. 1016-1022, 2018.

[33] J. K. Zhang, T. Zhu, X. R. Wang, S. N. Xiao, G. W. Yang, and B. Yang, "Comprehensive evaluation model for one-dimensional crash energy management of trains," Journal of Southwest Jiaotong University, 2020.

[34] H. J. Jang, K. B. Shin, and S. H. Han, "A study on the crashworthiness evaluation and performance improvement of tilting train carbody structure made of sandwich composites," Journal of The Korean Society for Composite Materials, vol. 24, no. 5, pp. 9-16, 2011.

[35] W. S. Seung, S. J. Hyun, and H. H. Jun, "A study on analysis of impact deceleration characteristics of railway freight car," Journal of the Korea Academia-Industrial cooperation Society, vol. 21, no. 3, pp. 32-38, 2020.

[36] T. Q. Nie, Z. S. Ren, S. G. Sun et al., "Research on collision safety of high-speed EMU," Railway Locomotive \& Car, vol. 35, no. 4, pp. 11-15, 2015.

[37] C. Cole, M. Spiryagin, Q. Wu, and Y. Q. Sun, "Modelling, simulation and applications of longitudinal train dynamics," Vehicle System Dynamics, vol. 55, no. 10, pp. 1498-1571, 2017.

[38] O. A. Chen, "Dynamic simulation of Taipei EMU train," Vehicle System Dynamics, vol. 30, no. 2, pp. 143-167, 1998.

[39] Z. Ding, Z. Zheng, and J. Yu, "A wave propagation model of distributed energy absorption system for trains," International Journal of Crashworthiness, vol. 24, no. 5, pp. 508-522, 2019.

[40] C. Baykasoglu, E. Sunbuloglu, S. E. Bozdag, F. Aruk, T. Toprak, and A. Mugan, "Crash and structural analyses of an aluminium railroad passenger car," International Journal of Crashworthiness, vol. 17, no. 5, pp. 519-528, 2012.

[41] H. Zhao, P. Xu, S. Jiang et al., "A novel design method of the impact zone of a high-speed train," International Journal of Crashworthiness, pp. 1-10, 2020.

[42] Y. Liu, B. Yang, S.-n. Xiao, T. Zhu, G. Yang, and R. Xiu, "Parameter study and multi-objective optimization for crashworthiness of a B-type metro train," Proceedings of the Institution of Mechanical Engineers - Part F: Journal of Rail and Rapid Transit, Article ID 095440972110082, 2021.

[43] B. H. Li, K. F. Wang, Y. W. Liu et al., "Research on crashworthiness of long series EMU based on EN15227 code," Journal of Dalian Jiaotong University, vol. 40, no. 2, pp. 1-6, 2019.

[44] S. Lu, P. Xu, K. B. Yan, S. G. Yao, and B. H. Li, "A force/ stiffness equivalence method for the scaled modelling of a high-speed train head car," Thin-Walled Structures, vol. 137, pp. 129-142, 2019.

[45] Y. Y. Lai, Detailed Explanation of Theory and Example of Isight Parameter Optimization, Beihang University Press, Beijing, China, 2012.

[46] G. Divine, H. J. Norton, R. Hunt, and J. Dienemann, "A review of analysis and sample size calculation considerations for Wilcoxon tests," Anesthesia \& Analgesia, vol. 117, no. 3, pp. 699-710, 2013.
[47] H. Li and T. Johnson, "Wilcoxon's signed-rank statistic: what null hypothesis and why it matters," Pharmaceutical Statistics, vol. 13, no. 5, pp. 281-285, 2014.

[48] W. P. Ye, Origin9.1 Technical Drawing and Data Analysis, China Machine Press, Beijing, China, 2015. 